\title{
Evaluation of Herbal Anti-Stressor Product (Restobal) during the Vaccination Stress in Buffaloes
}

\author{
S. Sivajothi ${ }^{1 *}$, Y.V. Prithvidhar Reddy ${ }^{2}$, B. Sudhakara Reddy ${ }^{2}$, S.Vani $^{3}$, \\ Swati Chandel ${ }^{4}$, Kotagiri Ravikanth ${ }^{4}$ and Bhaskar Ganguly ${ }^{4}$ \\ ${ }^{1}$ Department of Veterinary Parasitology, ${ }^{2}$ Department of Veterinary Clinical Complex, \\ ${ }^{3}$ Department of Animal Genetics and Breeding, College of Veterinary Science, Proddatur- 516 \\ 360, Y.S.R. Kadapa District, Sri Venkateswara Veterinary University, Andhra Pradesh, India \\ ${ }^{4}$ Clinical Research, Ayurvet Limited, Village: Katha, Baddi-173205, \\ Himachal Pradesh, India \\ *Corresponding author
}

\section{A B S T R A C T}

\section{Key w o r d s \\ Stress, Vaccination, Buffaloes, Restobal, Management \\ Article Info \\ Accepted: \\ 06 June 2018 \\ Available Online: \\ 10 July 2018}

\begin{abstract}
Vaccination is the best method for controlling the disease and the protection of the livestock. During the vaccination, most of the animals get stressed which will influence the development of the immunity against the vaccination. The present study was conducted to evaluate the herbal anti-stressor product (Restobal ${ }^{\circledR}, \mathrm{M} / \mathrm{s}$ Ayurvet Limited) against the management of vaccination stress in buffaloes. Buffaloes in treatment group administered with herbal anti stressors (Restobal) showed the significant changes by elevation of the glutathione peroxidase levels, total leukocyte and lymphocyte count and reduced cortisol levels when compared with the buffaloes in control group. It is observed that herbal anti stressor product (Restobal) can be recommended as a supportive therapy during the vaccination programmes in buffaloes.
\end{abstract}

\section{Introduction}

Foot-and-mouth disease is one of the highly contagious and economically important diseases in India. It is characterized by fever, depression, anorexia and excessive stingy or foamy salivation in the cloven-hoofed animals. Control of Foot-and-mouth disease becomes a challenge as soon as it infects a host as it replicates and spreads rapidly (Knight-Jones and Rushton, 2013). Vaccination is the best method for controlling disease and the protection of livestock from FMD. During the vaccination, most of the animals get stressed by the act of handling, the injection and the inflammatory reactions (Jo et al., 2014). It is very essential to reduce the stress during the period of vaccination for its best utilization (Trevisan et al., 2001). There is very limited literature is available in relation to the management of stress during the vaccination in buffaloes. Hence, the present study was conducted to evaluate the herbal anti-stressor product (Restobal ${ }^{\circledR}, \mathrm{M} / \mathrm{s}$ Ayurvet 
Limited) available in the market against the management of vaccination stress in buffaloes.

\section{Materials and Methods}

The Present study was conducted on the buffaloes presented to the veterinary dispensaries in and around Proddatur, YSR Kadapa District of Andhra Pradesh. Twenty buffaloes were selected and divided into two groups. Buffaloes in group I was vaccinated without any anti-stressor supplementation and serve as control group. Buffaloes were vaccinated with inactivated trivalent (virus types O, A, Asia 1) oil adjuvant Foot-andMouth disease vaccine. Buffaloes in group II were vaccinated and supplemented with oral herbal preparation $\left(\right.$ Restobal $^{\circledR}, \mathrm{M} / \mathrm{s}$ Ayurvet Limited @ $50 \mathrm{ml}$ orally BID for 5 days before and 5 days after vaccination) serve as the treatment group. The herbal anti stressor product Restobal comprises of herbs namely Ocimum sanctum, Withania somnifera, Phyllanthus emblica and many more in fixed concentration.

Whole blood and serum were collected on the $0^{\text {th }}$ day, $3^{\text {rd }}$ day and $5^{\text {th }}$ day of post-vaccination for laboratory analysis. Five milliliters of blood was collected in vacutainer tubes with ethylene diamine tetra acetate for haematological investigation. The parameters including packed cell volume (PCV), haemoglobin $(\mathrm{Hb})$, red blood cell count (RBC), white blood cell count (WBC) and differential counts (DC) were done as per standard methods and absolute count of DC was compared (Sivajothi et al., 2014). Five milliliters of venous blood was collected in vacutainer tubes without anticoagulant for the collection of serum. Serum cortisol levels and serum glutathione peroxidase levels were estimated by using commercially available kits. Buffaloes have monitored to the record the daily feed intake and leftover feed. The appetite of the individual buffaloes, rectal temperature, pulse rate, respiration rate and colour, consistency of faeces and faecal output was analysed. Data were presented as the mean \pm standard error (SE) and were subjected to statistical analysis using one-way analysis of variance by using SPSS version 15.0. Post hoc differences between means were tested by a multiple comparison Duncan test. Differences at $\mathrm{p}<0.05$ were considered significant.

\section{Results and Discussion}

Observed clinical, haematological, cortisol and glutathione peroxidase levels in control and treatment group were $\left(0^{\text {th }}\right.$ day, $3^{\text {rd }}$ day, $5^{\text {th }}$ day of vaccination) mentioned in the Table 1. Body condition score was not significantly variable to assess the difference between the two groups in the present study. In both the groups of buffaloes, reduction in the daily feed intake was noticed as a common finding and leftover roughage was noticed throughout the study period. Immediately after vaccination, buffaloes showed reduced milk production prior to the vaccination. But there is no difference in the milk yield in between the groups. An increased level of cortisol and rectal temperature, heart rate, pulse rate and respiratory rate level was observed after $5^{\text {th }}$ day of vaccination in buffaloes prior than vaccination which indicative of vaccination stress. Recorded haematological changes were in association with the previous literature (Shawky et al., 2016).

In the present study, buffaloes after $5^{\text {th }}$ day of vaccination showed reduced haemoglobin but in buffaloes treated with Restobal product showed the maintenance of normal levels. There is no variation in the packed cell volume of both the group of buffaloes. Elevated total erythrocyte count was recorded in the group II buffaloes which had a role in the development of the immunity. 
Table.1 Mean vital, haematological, serum cortisol and glutathione levels in control and treatment group buffaloes with Vaccination Stress (Mean \pm S.E.)

\begin{tabular}{|c|c|c|c|c|c|c|c|c|}
\hline \multirow{2}{*}{ S.No. } & \multirow{2}{*}{ Parameters } & \multicolumn{2}{|c|}{$0^{\text {th }}$ Day } & \multicolumn{2}{|c|}{$3^{\text {rd }}$ Day } & \multicolumn{2}{|c|}{$5^{\text {th }}$ Day } & \multirow{2}{*}{$\mathrm{P}$ value } \\
\hline & & $\begin{array}{c}\text { Control } \\
\text { (Group I) } \\
(\mathbf{N}=\mathbf{1 0})\end{array}$ & $\begin{array}{c}\text { Treatment } \\
\text { (Group II) } \\
(\mathbf{N}=\mathbf{1 0})\end{array}$ & $\begin{array}{c}\text { Control } \\
\text { (Group I) } \\
(\mathbf{N}=\mathbf{1 0})\end{array}$ & $\begin{array}{c}\text { Treatment } \\
\text { (Group II) } \\
(\mathbf{N}=\mathbf{1 0})\end{array}$ & $\begin{array}{c}\text { Control } \\
\text { (Group I) } \\
(\mathbf{N}=\mathbf{1 0})\end{array}$ & $\begin{array}{c}\text { Treatment } \\
\text { (Group II) } \\
(\mathbf{N}=\mathbf{1 0})\end{array}$ & \\
\hline 1 & Haemoglobin (g/dl) & $11.27 \pm 0.18$ & $11.36 \pm 0.21$ & $10.79 \pm 0.19$ & $10.90 \pm 0.17$ & $10.29 \pm 0.12$ & $11.05 \pm 0.12$ & $0.042 *$ \\
\hline 2 & $\mathrm{PCV}(\%)$ & $35.8 \pm 0.94$ & $35.9 \pm 1.11$ & $35.1 \pm 0.86$ & $35.7 \pm 1.7$ & $35.3 \pm 1.07$ & $35.9 \pm 1.35$ & $0.733^{\mathrm{NS}}$ \\
\hline 3 & TEC $\times 10^{6} \%$ cumm & $6.45 \pm 0.13$ & $6.48 \pm 0.12$ & $6.31 \pm 0.12$ & $6.26 \pm 0.13$ & $6.06 \pm 0.13$ & $6.5 \pm 0.16$ & $0.048 *$ \\
\hline 4 & TLC /cumm & $8166.2 \pm 126.3$ & $8666.9 \pm 232.2$ & $8630.7 \pm 128.1$ & $9413.7 \pm 156.4$ & $8878.4 \pm 225.5$ & $9810.3 \pm 147.2$ & $0.003 * *$ \\
\hline 5 & Neutrophils /cumm & $2490.63 \pm 118.2$ & $2643.3 \pm 110.9$ & $2511.4 \pm 98.48$ & $2852.3 \pm 120.31$ & $2769.9 \pm 102.62$ & $2864.5 \pm 88.46$ & $0.730^{\mathrm{NS}}$ \\
\hline 6 & Lymphocytes /cumm & $5096.6 \pm 215.2$ & $5407.6 \pm 198.2$ & $5203.9 \pm 101.47$ & $5694.5 \pm 109.34$ & $5459.9 \pm 118.6$ & $6072.4 \pm 98.27$ & $0.020 *$ \\
\hline 7 & Monocytes /cumm & $342.9 \pm 40.4$ & $381.4 \pm 31.16$ & $362.4 \pm 30.13$ & $385.9 \pm 72.27$ & $399.5 \pm 59.3$ & $392.4 \pm 60.2$ & $0.120^{\mathrm{NS}}$ \\
\hline 8 & Eosinophils /cumm & $220.5 \pm 19.15$ & $242.6 \pm 9.24$ & $250.3 \pm 21.29$ & $272.9 \pm 34.23$ & $319.6 \pm 31.22$ & $294.3 \pm 41.21$ & $0.060^{\mathrm{NS}}$ \\
\hline 9 & Basophil /cumm & $48.99 \pm 7.16$ & $51.99 \pm 6.16$ & $43.15 \pm 9.16$ & $65.89 \pm 11.15$ & $71.02 \pm 10.13$ & $49.05 \pm 11.16$ & $0.180^{\mathrm{NS}}$ \\
\hline 10 & Cortisol (nmol/L) & $23.01 \pm 1.1$ & $18.01 \pm 1.04$ & $32.75 \pm 5.67$ & $22.29 \pm 3.24$ & $42.46 \pm 5.08$ & $30.39 \pm 2.74$ & $0.000 * *$ \\
\hline 11 & Temperature $\left({ }^{\circ} \mathrm{F}\right)$ & $99.5 \pm 0.24$ & $99.5 \pm 0.11$ & $100.3 \pm 0.21$ & $100.1 \pm 0.04$ & $100.8 \pm 0.22$ & $100.7 \pm 0.22$ & $0.860^{\mathrm{NS}}$ \\
\hline 12 & Heart rate & $71.5 \pm 1.02$ & $71.3 \pm 1.7$ & $74.3 \pm 1.1$ & $75.2 \pm 1.8$ & $78.5 \pm 1.6$ & $79.3 \pm 1.5$ & $0.724^{\mathrm{NS}}$ \\
\hline 13 & Pulse rate & $71.2 \pm 0.94$ & $70.3 \pm 1.5$ & $73.8 \pm 0.78$ & $74.6 \pm 1.7$ & $77.7 \pm 1.54$ & $78.0 \pm 1.54$ & $0.892^{\mathrm{NS}}$ \\
\hline 14 & Respiratory rate & $19.6 \pm 0.7$ & $18.6 \pm 0.58$ & $20.5 \pm 0.83$ & $20.0 \pm 0.51$ & $23.2 \pm 0.8$ & $20.2 \pm 0.86$ & $0.025 *$ \\
\hline 15 & $\begin{array}{l}\text { Glutathione } \\
\text { peroxidase }(\mathrm{u} / \mathrm{ml})\end{array}$ & $41.3 \pm 1.05$ & $44.94 \pm 1.39$ & $36.40 \pm 1.37$ & $42.60 \pm 1.30$ & $31.1 \pm 1.15$ & $42.42 \pm 1.21$ & $0.000 * *$ \\
\hline
\end{tabular}

NS: Statistically Not Significant ( $>0.05) ; *$ Statistically Significant $(\mathrm{P} \leq 0.05) ; * *$ : Statistically Highly Significant $(\mathrm{P} \leq 0.01)$ 
Significant elevation in the total leukocyte count and lymphocyte count was observed when compared with the buffaloes in group I on $5^{\text {th }}$ day of therapy.

Cortisol is considered as the stress assessing hormone which secreted in higher levels during the stress response. In the present study, stress may be due to different strains in the vaccine. Stress of vaccination in some cases has been shown to trigger a latent infection into a clinical disease (Doel, 2003). In group II buffaloes were showed the reduced levels of cortisol when compare to the group I which indicates that the group II buffaloes had less stress vaccination. During the stress period, Reactive Oxygen Species (ROS) was noticed to mediate oxidative stress in farm animals. As a consequence, the body employs antioxidants to quench these free radicals. Glutathione peroxidase is one of the main constituents of intracellular antioxidant defense system in bovines (Sivajothi and Reddy, 2017). In the present study increased levels of glutathione peroxidase levels was noticed in Group II which indicates they were free from reactive oxygen species radicals when compare with the group I buffaloes. Lymphocytosis is the result of enhancement of the B cell function for antibody formation as indicated in the present study by increased gamma globulins and which also attributed to the stress response as a result of endogenous release of cortisol which plays a major role in regulating circulating concentration of leukocytes (Kumar and Sharma, 2010). Efficacy of the same herbal anti stressor product was utilised to increase the immunity after vaccination in small ruminants (Ramana et al., 2013).

There is an elevation of the glutathione peroxidase levels, reduction in the cortisol levels in group II buffaloes when compare with the group I buffaloes. Elevation of the total leukocyte count was more in the treatment group which had a role in immune response after vaccination. Assessment of the stress parameters proved that the buffaloes with Restobal $^{\circledR} \quad(\mathrm{M} / \mathrm{s}$ Ayurvet Limited) treatment showed less stress compared with the buffaloes in the control group. It is recommended that bovines during the time of vaccination, Restobal can be administered as supportive therapy before starting of the vaccination which helps the buffaloes to reduced stress and attain the excellent immunity against the particular vaccination.

In conclusion, herbal product $\left(\right.$ Restobal $^{\circledR}, \mathrm{M} / \mathrm{s}$ Ayurvet Limited) is recommended along with the vaccination in buffaloes to prevent the vaccination stress.

\section{Acknowledgement:}

The authors are thankful to the authorities of Sri Venkateswara Veterinary University, Tirupati for providing the facilities to carry out the research.

\section{References}

Doel, T.R.2003. FMD Vaccines. Virus Research, 91: 81-99.

Jo, N.C., Jung, J., Kim, J.N., Lee, J., Jeong, S.Y., Kim, W., Sung, H.G., Seo, S.2014. Effect of vaccination against foot-and-mouth disease on growth performance of Korean native goat (Capra hircus coreanae), J Anim Sci., 92: 2578-2586.

Knight-Jones, T.J.D., Rushton, J. 2013. The Economic Impacts of Foot and Mouth Disease -What Are They, How Big Are They and Where Do They Occur? Preventive Veterinary Medicine., 112: 161-173.

Kumar, V. Sharma, A. 2010. Neutrophils: Cinderella of Innate Immune System. International Immunopharmacology, 10: $1325-1334$. 
Ramana, D.B.V., Saxena, M.J., Ravikanth, K., Thakur, A., Maini, S. 2013. Post vaccination immune response Potentiation with Restobal in lambs and sheep. International Journal of Current Research, 5 (12): 3591-3593.

Shawky, S.M., Thabet, N.S., Orabi, S.H., Nayel, M.A. 2016. A comparative study on the hemato-biochemical and immunological effects of the hexavalent FMD vaccine alone or in combination with trivalent FMD vaccine in cattle, $\mathrm{J}$ Biosci Med (Irvine), 4: 16-26.

Sivajothi, S., Reddy, B.S. 2017. Antioxidant status and electrocardiographic changes in buffaloes with Trypanosoma evansi infection, Chem Sci Rev Lett. 6(24): 2573-2576.

Sivajothi, S., Reddy, B.S., Kumari, K.N., Rayulu, V.C. 2014. Haematological changes in Trypanosoma evansi infected cattle. International Journal of Scientific World, 2: 27-30.

Trevisan, M., Browne, R., Ram, M., Muti, P., Freudenheim, J. 2001. Correlates of markers of oxidative status in the general population. Annual Journal of Epidemiology, 154:348-356.

\section{How to cite this article:}

Sivajothi, S., Y.V. Prithvidhar Reddy, B. Sudhakara Reddy, S. Vani, Swati Chandel, Kotagiri Ravikanth and Bhaskar Ganguly. 2018. Evaluation of Herbal Anti-Stressor Product (Restobal) during the Vaccination Stress in Buffaloes. Int.J.Curr.Microbiol.App.Sci. 7(07): 723-727. doi: https://doi.org/10.20546/ijcmas.2018.707.088 